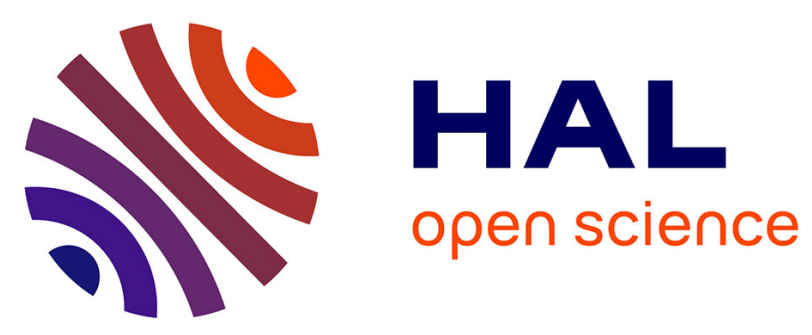

\title{
Facebook Posts Engagement Analysis - Case Study of the Leading e-Shop in the Czech Republic
}

\author{
Antonin Pavlicek, Petr Doucek, Richard Novák
}

\section{To cite this version:}

Antonin Pavlicek, Petr Doucek, Richard Novák. Facebook Posts Engagement Analysis - Case Study of the Leading e-Shop in the Czech Republic. 12th International Conference on Research and Practical Issues of Enterprise Information Systems (CONFENIS), Sep 2018, Poznan, Poland. pp.27-39, 10.1007/978-3-319-99040-8_3 . hal-01963053

\section{HAL Id: hal-01963053 \\ https://hal.inria.fr/hal-01963053}

Submitted on 21 Dec 2018

HAL is a multi-disciplinary open access archive for the deposit and dissemination of scientific research documents, whether they are published or not. The documents may come from teaching and research institutions in France or abroad, or from public or private research centers.
L'archive ouverte pluridisciplinaire HAL, est destinée au dépôt et à la diffusion de documents scientifiques de niveau recherche, publiés ou non, émanant des établissements d'enseignement et de recherche français ou étrangers, des laboratoires publics ou privés. 


\title{
Facebook Posts Engagement Analysis - Case Study of the Leading e-Shop in the Czech Republic
}

\author{
Antonin Pavlicek ${ }^{1[0000-0002-1230-5982]}$, Petr Doucek $^{2}$, Richard Novák ${ }^{3}$ \\ ${ }^{1,2}$ University of Economics, Prague, Czech Republic \\ \{antonin.pavlicek, doucek\}@vse.cz \\ ${ }^{3}$ T-Mobile Czech Republic, Prague, Czech Republic \\ richard.novaket-mobile.cz
}

\begin{abstract}
.
This study examines shopping behavior and customers' interests based on analysis of the content of Facebook posts. Identifies types of the post which are more likely to inspire purchase. Two main methods were used: a content analysis of posts on a Facebook page connected with data from marketing department and statistical analysis of these data. Posts were categorized by selected quantitative and qualitative criteria. Four research questions were selected, all hypotheses were evaluated by ANOVA and regression analysis. Findings: the relation between posts' reactions on Facebook and revenues was not confirmed. Some relation between negative reactions and visits was found. The more negative reactions the more visits with quite high probability according to calculated correlation. Positive reactions do not correlate significantly with the number of visits. In case of a number of posts in categories dependence, a number of functional brand posts are dependent on the number of experiential brand posts and a number of sales promotion posts are dependent on the number of functional brand posts. Implications: Improve targeted advertising, carefully watch what types of post publish on social media, focus also on types of posts like employee, cause-related, experiential and customer relationship that should be used more and possibly combined with functional and emotional types of posts and watch out for positive and/or negative reactions more according to the results.
\end{abstract}

Keywords: Social Networking Sites, Post Analysis, Data Analysis, Marketing

\section{Introduction}

When discussing advertising and marketing strategy today the discussion would be incomplete without considering the use of social media. [1] Users of Social media follow different brands on fan pages and more than 50\% users monitor brands on social media. Now users are not only receiving information online, they are also actively engaged in contributing their actions in brand communications activities. The emergence of social 
media has changed the consumers' role in storytelling from that of a passive listener to a more active participant. [2], [3], [4], [5] There are different types of consumer brandrelated activities and each one implies a different level of involvement. Social media marketing is different than traditional methods of marketing; therefore, it requires special attention and strategy building to achieve brand image and loyalty. [6]

By creating a fan page within Facebook, companies can profit from a range of technical features. Prior research highlights that these technical features allow for a viral distribution and an interactive exchange of information. First, a company can initiate the interaction with users by publishing a company wallpost, i.e., writing on a fan page's message board (so-called "wall"). Thereby, companies can choose between a range of media types (e.g., status, link, photo, or app wallpost) in order to spread information, the most adequate way. Second, also the users of Facebook can interact with a company, for example by commenting on a company wallpost (Rahman et al., 2016).

Many studies have been conducted on fanpages contents in terms of generating likes, comments or shares. One study results suggested that the richness of the content (inclusions of images and videos [7]) raises the impact of the post in terms of likes. On the other hand, using images and a proper publication time are significantly influencing the number of comments, whereas the use of links may decrease this metric. The findings indicate that brand post vividness has a significant positive effect on brand post shares, but not on brand post likes. Brand post interactivity has a significant negative effect on both brand post likes and brand post shares. Brand post novelty and brand post consistency have a significant positive effect on both brand post likes and brand post shares. Finally, brand post content type has a significant positive effect on brand post likes, but not brand post shares. Results suggest the more richness of the content; the more likes and comments it gains. Moreover, comparing among four benefits components, a hedonic benefit is the most effective type of content that affects word-of-mouth most. As for publication time of the content, it is partly significantly influencing word-of-mouth. [6], [8], [9],

Many approaches to posts categorizing on brand pages have been developed. Tafesse and Wien [10] processed an extensive review of literature focused on posts categorization. The authors identified 3 different ad hoc approaches and concluded that any systematic approach could be found. Based on this result they performed formalized analysis to create a generalized typology of posts.

The main criticism of analyzed approaches comes from inadequacy and ineffectiveness of categories. For example, the first mentioned categorization consists of entertainment, information and transaction domain (e.g. [11]; [12]). Using this approach problems to categorize social issues or brand image posts appear. Therefore, it is not possible to categorize every post. The second approach (e.g. [13]; [14]) is invalid because of its selective emphasis on few message strategies while ignoring several legitimate ones [10, p. 6]. The third one basically uses categories focused only on subjective meaning ascribed to posts like social, functional, hedonic etc. (e.g. [15]; [16]; [17], [18])

Another example from the local market research was found focused on the identification of types and frequencies of posts added by e-shops Alza.cz, Czc.cz and Mironet.cz [19]. The authors used qualitative criteria [19, p. 10]: 
- Product: information promoting products.

- Contest: contests for fans of the page.

- Benefits: price reductions, free products.

- News and Information: company, branches, job positions.

- Other: not classifiable within categories 1-4.

\section{Methodology}

\subsection{Subject of analysis}

The subject of interest is a Czech e-shop company Alza.cz which operates since 1994. They offer a wide range of products, especially consumer electronics. Through years it expanded into 3 other states - Slovakia, Hungary, Austria, and currently has 49 outlets and 78 AlzaBoxes with more than 15,000 employees. Their turnover rose exponentially through the years and for last accounting period they earned nearly 21 billion Czech crowns.

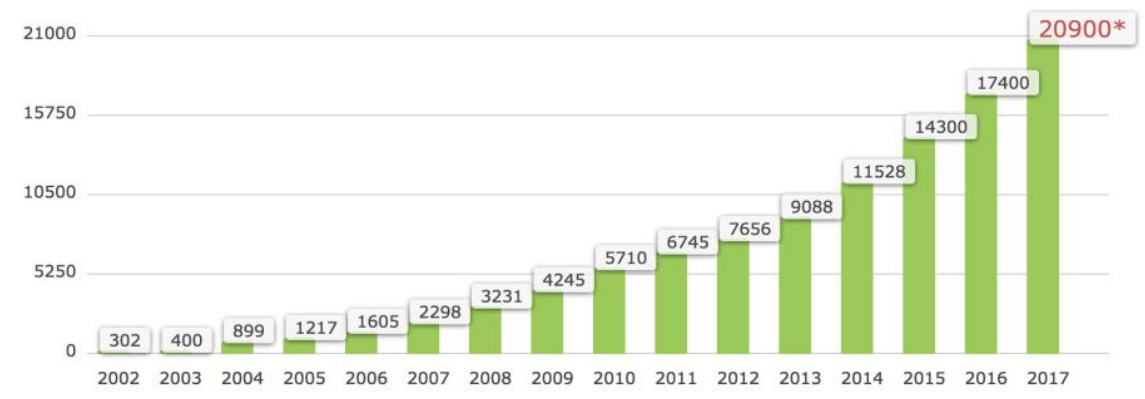

Figure 1. The annual turnover of Alza in CZK million excluding VAT, source [20]

The analysis itself focused on finding some correlation between 2 types of data connected to the company - posts on Alza's page on social network Facebook and official Alza's marketing data gained from Google Analytics corresponding to these posts. The data were collected for the period from October 2016 to March 2018.

\subsection{Research questions and hypotheses}

The research itself was based on setting most viable questions of interest and hypothesis. These questions were created accordingly to previously selected quantitative categories. The character of these question reflects opinions of the potential customers on Alza's marketing strategy on Facebook.

- What types of posts are the most and the least common? 
- What types of posts are the most and the least commented or liked?

- What types of posts have the most and the least reactions (likes and comments combined)?

- What kind of other interesting deviations can be observed among values of the criteria (positive or negative reactions, shares, users, visits, transactions, revenue etc.)?

Following hypothesis were based on the interesting results of questions above.

H1: Posts with a higher number of reactions contribute to higher revenues.

This hypothesis is based on the results of the question 3 which examines the number of total reactions. It tests whether the median value of revenues for individual intervals of reactions matches against the alternative that revenues increases with growing number of reactions. This hypothesis is crucial for the whole project since one of its goals is to discover if a number of reactions influence the shopping behavior.

H2: The \# of posts of group $\mathrm{X}$ depends on \# of posts (group Y).

Testing of this hypothesis is being performed in following categories: Functional Experimental and Functional - Sales. It follows an examination of the H1 hypothesis because it also requires dividing the posts by the number of reactions.

H3: Number of visits depends on positive/negative reactions on posts.

This analysis considers the influence of positive/negative reaction on motivation of the potential customer to visit the Alza's web page. It requires the division of the posts into intervals by numbers of reactions as well. The hypothesis is being analyzed separately for positive and negative reactions.

\section{Research}

What types of posts are the most and the least common?

All 999 posts were assigned to set 12 qualitative categories based on their content. The rule is that every post must be categorized at least into 1 category and simultaneously every post could be assigned to multiple categories. Below is a graph, showing the distribution of the posts in all categories, displayed in percentage. Table 1 shows that majority of posts represents Functional brand posts (523 posts) followed by Sales promotion posts (468 posts). The category with the lowest amount of posts is the Causerelated brand posts. In total, 737 out of 999 posts belong either to category Functional brand or Sales promotion. The total amount of posts by category is shown below.

Table 1. Percentage of posts in categories, source (authors)

\begin{tabular}{lrr} 
Category & Percentage & Quantity \\
\hline Emotional brand posts & $23.32 \%$ & 233 \\
\hline Functional brand posts & $52.35 \%$ & 523 \\
\hline Educational brand posts & $9.01 \%$ & 90 \\
\hline
\end{tabular}




\begin{tabular}{lrr}
\hline Brand resonance & $13.21 \%$ & 132 \\
\hline Experiential brand posts & $7.91 \%$ & 79 \\
\hline Current event. & $13.11 \%$ & 131 \\
\hline Personal brand posts & $8.41 \%$ & 84 \\
\hline Employee brand posts & $5.41 \%$ & 54 \\
\hline Brand community & $5.71 \%$ & 57 \\
\hline Customer relationship & $9.91 \%$ & 99 \\
\hline Cause-related brand posts & $3.40 \%$ & 34 \\
\hline Sales promotion & $46.85 \%$ & 468
\end{tabular}

\section{What types of posts are the most and the least commented or liked?}

The highest average number of comments have the posts from category Customer relationship. It is more than 83 comments per post. They are often combined with posts from the category Functional posts and Sales promotion posts. These types of posts should encourage users to create a comment or evaluate them. It is proved that the results correspond to the character of the post. On the other hand, the posts from categories Functional posts or Sales promotion are not very commented.

Second most commented type of posts is the category Experiential brand posts which is frequently combined with categories Functional brand post or Current event. They have around 55 comments per post. In the case of combination with the category Current event, the number of posts is decreasing compared to the combination with Functional brand posts, or in some cases even with category Brand resonance. These results evoke that users will more likely react to posts which advertise some actions. In case of Alza, they are usually fan events, festivals, product launches etc. Sometimes it is only a simple provocation to some activity such as sport. If the post contains a product or brand resonance elements, the possibility of commenting is higher.

The least commented category is Educational brand posts which are usually combined with Functional brand posts, occasionally with Sales promotion posts. However, the combination does not increase the number of comments. Surprisingly, Emotional posts are not being commented as often as expected. The number of comments is averagely around 37 comments per post. On the other hand, category Emotional is on the third place in case of a number of likes. A higher number of likes is typical also for the category Employee brand posts and Cause-related posts. This might be caused by the different content of these posts. They focus more on social message then the others.

What types of posts have the most and the least reactions (likes and comments combined)?

Most average number of reactions per post has the category Cause-related brand posts (248 reactions per post) followed by Employee brand post (247 reactions per post) and Emotional brand posts (210 reactions per post). Based on the character of these it is obvious that users react more to information about people, social themes or programmes run by Alza. Noteworthy is also the category Experiential brand spots with around 179 reactions per posts and Customer relationship with 162 reactions per post. 
Categories such as Personal brand posts, Current event or Educational brand posts, also Functional brand posts and Sales promotion have the lowest number of reactions. In summary, posts which relate to products evoke a lower number of reactions.

a. Are there any other interesting deviations among values of the criteria (positive or negative reactions, shares, users, visits, transactions, revenue etc.)?

Purpose of this questions is to find any interesting facts that emerge from collected data. The most shared posts are the ones with emotional background or which evoke some activities or experiences. Also, the significant number of shares is seen within the posts which propagate festivals or sponsored events. The level of sharing is not high, it is 1116 shares per posts. Other categories are even lower.

Controversial results bring a comparison of the positive and the negative reactions. Category Employee brand posts have the highest number of positive (129 reactions per post) and simultaneously negative reactions ( 8 reactions per post). It is important to emphasize that in case of Employee brand posts there are only 3 posts with a high number of negative reactions and the rest of posts reached no negative reactions or very low number of them. Other categories have again a very low number of negative reactions. For that reason, it is not possible to define the category which evokes a negative response. In general, posts with personal information about Alza (staff, programmes etc.) are more interesting for users. Important is the emotional character of the post as well. Another interesting result was discovered in case of new users of Alza's webpage. Post in the category Cause-related brand posts generates the highest number of new users. Per one post is up to around 1130 users. An interesting fact is that Cause-related brand posts represent category with the lowest number of post and is being combined frequently with Employee brand posts or Emotional posts which implies that users are attracted to interesting programs, social themes, new partnerships and company's staff. It leads them to visit the official web page of Alza.

Analysis of the average revenue per post shows that highest earning category is Brand resonance. One post from this category earned averagely $155,000 \mathrm{CZK}$. The second most profitable category is Experiential brand posts with revenue around 125,000 CZK per post. Current event and Sales promotion posts yield approximately 85,000 CZK. Post from category brand resonance with revenues over 100,000 CZK was combined mainly with categories Sales promotion posts, Emotional posts, and Current Event. In the case of Experiential brand post, the highest revenues occurred in combination with categories Functional brand posts or Sales promotion posts.

The results change a little when the revenues are being related to individual transactions. Focusing on the most profitable transactions by categories, the Cause-related posts and Experiential brand posts are the best. They earned over $70 \mathrm{CZK}$ per transaction per post. The worst is Functional brand post with the revenue around $6 \mathrm{CZK}$ per transaction. The highest profits from Cause related post category brings the combination with other categories such as Sales promotion category, Employee brand posts, Brand resonance, Functional brand posts or Emotional. Posts from Experiential brand posts has the most profitable transactions in connection with Functional brand posts, Brand resonance, Sales promotion posts and Emotional. Current event posts might have its influence on the profit as well. 


\section{$4 \quad$ Results}

Posts with a higher number of reactions contribute to higher revenues on sales

This hypothesis tested the influence of a number of reactions per post on revenues generated from them. For this purpose, reactions were divided into intervals by Sturges rule. The revenues were calculated within these intervals. The analysis of variance (ANOVA) was used to effectively compare the revenues in the individual groups. Due to a large number of posts and outlying values (wide range of revenues), intervals 0-13, 66-78, 118-130 and 235+ were not added to the test. Interval 196-208 was also not included because it did not meet the minimum number of values in the group (at least five).

The following hypothesis was creates for this analysis of variance (ANOVA):

- H0: median values (means) of revenues/ 1 post from individual intervals of numbers of reactions matches

- H1: median values (means) of revenues/ 1 post from individual intervals of numbers of reactions differs

The test was run in MS Excel program on 5\% level of significance Anova: one factor

Table 2. H0 Anova analysis, source (authors)

\begin{tabular}{rrrrr}
\multicolumn{1}{r}{ Selection } & Number & \multicolumn{1}{c}{ Sum } & Average & Range of scatter \\
\hline $\mathbf{1 4 - 2 6}$ & 178 & 12539060 & 70444.16 & $4.82 \mathrm{E}+10$ \\
\hline $\mathbf{2 7 - 3 9}$ & 117 & 4404190 & 37642.65 & $2.4 \mathrm{E}+09$ \\
\hline $\mathbf{4 0 - 5 2}$ & 76 & 4687526 & 61677.98 & $6.89 \mathrm{E}+09$ \\
\hline $\mathbf{5 3 - 6 5}$ & 60 & 3564573 & 59409.55 & $5.76 \mathrm{E}+09$ \\
\hline $\mathbf{7 9 - 9 1}$ & 25 & 982643.9 & 39305.76 & $1.94 \mathrm{E}+09$ \\
\hline $\mathbf{9 2 - 1 0 4}$ & 21 & 841505.5 & 40071.69 & $2.08 \mathrm{E}+09$ \\
\hline $\mathbf{1 0 5 - 1 1 7}$ & 24 & 1009070 & 42044.6 & $1.69 \mathrm{E}+09$ \\
\hline $\mathbf{1 3 1 - 1 4 3}$ & 16 & 1580152 & 98759.48 & $6.91 \mathrm{E}+10$ \\
\hline $\mathbf{1 4 4 - 1 5 6}$ & 14 & 1085833 & 77559.5 & $1.56 \mathrm{E}+10$ \\
\hline $\mathbf{1 5 7 - 1 6 9}$ & 6 & 179700.4 & 29950.06 & $8.56 \mathrm{E}+08$ \\
\hline $\mathbf{1 7 0 - 1 8 2}$ & 13 & 448008.6 & 34462.2 & $1.46 \mathrm{E}+09$ \\
\hline $\mathbf{1 8 3 - 1 9 5}$ & 12 & 465720 & 38810 & $2.45 \mathrm{E}+09$ \\
\hline $\mathbf{2 0 9 - 2 2 1}$ & 16 & 1053105 & 65819.05 & $9.49 \mathrm{E}+09$ \\
\hline $\mathbf{2 2 2}-234$ & 9 & 427417.8 & 47490.87 & $2.91 \mathrm{E}+09$
\end{tabular}

Table 3. H0 ANOVA analysis results, source (authors)

ANOVA

\begin{tabular}{lllllll}
\hline Variability source & SS & Difference & $M S$ & $F$ & P-value & $F$ crit \\
\hline Interselections & $1.4802 \mathrm{E}+11$ & 13 & $1.14 \mathrm{E}+10$ & $\mathbf{0 . 5 8 0 3 6 3}$ & $\mathbf{0 . 8 7 0 6 1 0 1 4}$ & $\mathbf{1 . 7 3 7 2 5 1 7}$ \\
All selections & $1.1242 \mathrm{E}+13$ & 573 & $1.96 \mathrm{E}+10$ & & &
\end{tabular}


P-value of the test is approximately 0.871 - higher than the alpha level of significance (0.05) and hence we do not reject the hypothesis $\mathrm{H} 0$ about the equivalents of median values of revenues in individual intervals divided by a number of reactions. That implies that in terms of revenues it does not matter on the number of reactions.

\section{The number of posts of group $\mathrm{X}$ depends on the number of posts of group $\mathrm{Y}$}

This hypothesis examines if exist any dependency between two different categories. Previous division of the posts into intervals was used again. Firstly, pairs of categories with thematically related content were selected

- Cause-related and Brand resonance

- Cause-related and Employee

- Experiential - Functional

- Functional - Sales

The goal was to discover if the number of posts in the first category depends on the number of post in the second category. Test was done by regression analysis. For the bad results following pair were excluded

- Cause-related and Brand resonance

- Cause-related and Employee

For the following analysis, the EViews statistical program was used. First tested pair was functional-experiential. The level of significance is $5 \%$. linear regression was performed in EViews:

Table 4. Linear regression analysis of pair number 1, source (authors)

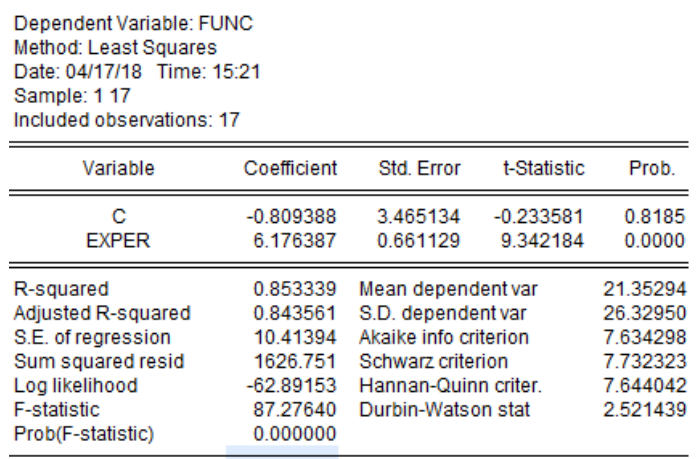

The most important outcome is the F-test which is represented by the lines F-statistic and Prob(F-statistic) - p-value of the test. Since the p-value is lower than the alpha level of significance, we reject the $\mathrm{H} 0$ in favour of the $\mathrm{H} 1$.

Other important criteria are the partial t-test; they relate directly to individual parameters. The p-value of the test is compared to the level of significance again. In the case of constant, we do not reject H0. Constant is statistically unimportant.

Another important indicator is the coefficient of determination (R2). It expresses how many percents of the variability of the explained variable was explained by the 
model. It highest number is required. In this case, the coefficient of determination is 0.853. It implies that $85.3 \%$ of the variability of the variable Functional bran post was explained by the model. The number is satisfying.

The square root of coefficient of determination is correlative coefficient which describes the dependency between two variables. In this regression, it is 0.923 which means strong dependency between selected variables. In summary, on the $5 \%$ of the level of significance, the number of posts of the category functional brand posts depends on a number of posts of the category Experiential brand posts.

The second tested pair was Functional brand posts and Sales promotion posts. The category of sales is considered as an explained variable. The analysis was performed in EViews again.

Table 5. Linear regression analysis of the pair number 2, source (authors)

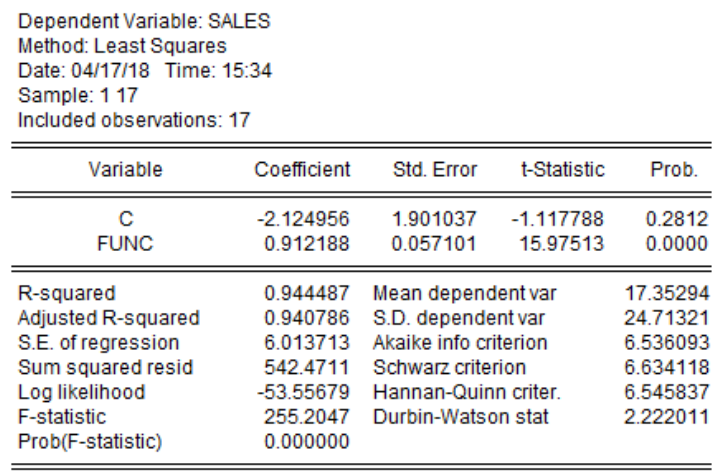

P-value of the F-test is again very small. In fact, it is less than the alpha level of significance, so we do reject $\mathrm{HO}$ - the model is appropriate. When it comes to t-test of tested parameters, regression coefficient is statistically important, constant is on the other hand statistically unimportant. The coefficient of determination R2 is 0.944 . After the extraction of the square root, the correlative coefficient is 0.972 . It implies very strong dependency between tested variables. It was proved on the $5 \%$ of the level of dependency that number of Sales depends on the number of Functional posts.

\section{Number of visits depends on positive/negative reactions on posts}

The last hypothesis analyses the influence of positive/negative reactions on the turnout of individual posts. It is being explored whether a number of visit of individual posts depends on the number of positive/negative reactions. As in the previous sections, the analysis was performed within the intervals that were created by constructing the equation of average revenues hypothesis. Because of the distant values of visits, intervals $\langle 0.13\rangle,\langle 14.26\rangle$ and $\langle 235$ and more) were excluded from testing.

The analysis is performed in the statistical program EViews in the form of linear regression. 
Table 6. Linear regression analysis - H3, source (authors)

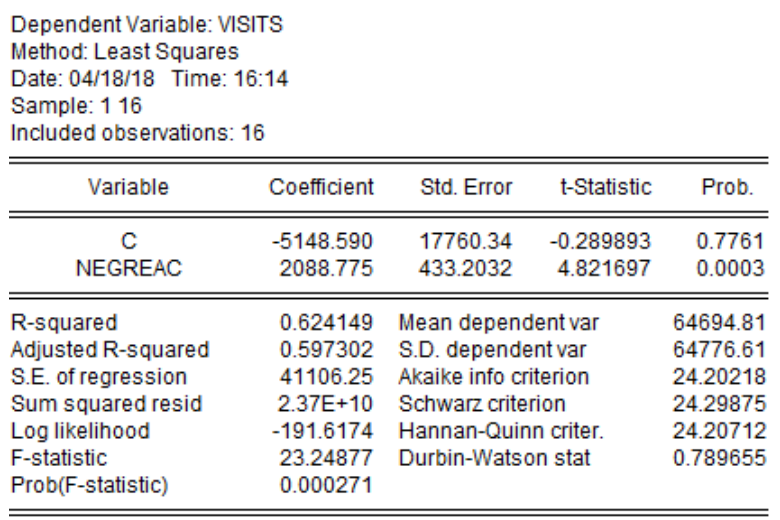

P-value of the test is 0.000271 which is less than the alfa level of significance, we reject the $\mathrm{H} 0$ and consider the model as appropriate. Unfortunately, other values are not so "positive". The partial test confirms that constant is statistically unimportant. Nevertheless, the value of the coefficient of determination is in this case only 0.624 . That means that only $62.4 \%$ of the variability of the variable Visits is explained by the model, which is not very good. On the other hand, after the extraction of the square root of coefficient of determination $\mathrm{R}^{2}$, the value of the correlative coefficient is approximately 0.79 . That signalizes strong dependency. On the $5 \%$ level of significance, it is possible to declare that number of visits depends on the number of negative reactions.

\section{Conclusion}

The first conclusion is not surprising at all. Posts connected to sales promotion and/or products themselves in various forms of displaying the product, teasing the product or even reviewing the product, tend to prevail drastically - in total 737 out of 999 posts. Significant categories from the point of view of likes, comments, shares, visits, and revenues are also Cause-related brand posts, Employee brand posts, Experiential brand posts and possibly Emotional and Brand posts.

According to the first hypothesis's result, the relation between posts' reactions on Facebook and revenues was not confirmed. These two values are highly probably not dependent. It means that trying to increase reactions on posts on Alza's Facebook to increase revenues is not the best solution and rather other factors should be considered.

On the other hand, there is some relation between negative reactions and visits. The more negative reactions the more visits with quite high probability according to calculated correlation. Positive reactions do not correlate significantly with a number of visits, so it is assumed that content which provokes negative reactions like resistance, anger or disagreement is more likely to increase the number of visits of Alza's web page. Positivity does not provoke to explore products, to visit Alza's web page and leaves the customers without any further interesting actions from the point of view of shopping behavior. This result is very interesting, usual and has potential to be researched more.

Alza uses to combine mainly functional, sales and emotional posts but based on the first research on data also experiential posts is a considerable category. It was found 
out that a number of functional brand posts is dependent on the number of experiential brand posts and number of sales promotion posts is highly dependent on the number of functional brand posts. Therefore, among these categories is significant relation so usually when Alza promotes sales the posts include information on product or product presentation and experiential brand posts are often focused on product launches or different activities or sense perception but also connected with products. So, discounts, customer contests, activities presented, experiences and feelings evoked are closely connected to products what is not very surprising for Alza as an e-shop but very typical.

Discussed findings can be concluded with more specific recommendations for Alza's activity on Facebook. The first is to improve targeted advertising. More reactions do not ensure more revenues, but the specified types of posts may increase visits and then possibly also increase the number of purchases. The second mentioned was not analyzed, however, targeted advertising on Alza's page may consequently persuade customers to stay and buy. Of course, this relation can be the subject of further research.

The second recommendation is to carefully watch what types of posts Alza publishes on Facebook (and possibly other social media). Focus also on types of posts like employee, cause-related, experiential and customer relationship that should be used more plus combined with functional or sales and especially Alza should stay using emotional type. In the Alza's case, it seems to be a positive factor because of a number of comments, likes, shares and positive reactions. The proper combination of these types of posts may result in the higher number of reactions and a higher number of new users at least.

The third recommendation is to watch out for positive and/or negative reactions more. It is not needed to post only negatively perceived posts to increase the number of visits but decide the right approach to handle with positive and negative reactions and the extent of posts generating different reactions used in different periods of time. It may be interesting to find out reasons for visiting and not visiting Alza and analyze deeper relations to again improve targeted marketing and customer relationships.

\section{Acknowledgment}

Paper was processed with the contribution of long-term support of scientific work on Faculty of Informatics and Statistics, University of Economics, Prague and thanks to help of New Media course students. 


\section{References}

[1] A. Pucihar, T. Pitner, and J. Ministr, Innovation and Diversity, vol. 46. Linz: Trauner Verlag, 2017.

[2] A. Pucihar, M. Praprotinik, M. Marolt, G. Lenart, and M. K. Borstnar, Use of Social Media in Tourism - Preliminary Results from Gorenjska Region in Slovenia. Liberec: Technical Univ Liberec, Faculty Economics, 2016.

[3] F. Sudzina, Escapist Motives for Playing Facebook Games: Fine-Tuning Constructs, vol. 42. Linz: Universitatsverlag Rudolf Trauner, 2013.

[4] T. Feige and M. Potancok, Enterprise Social Networks as a Tool for Effective Collaboration in Health Care Facilities, vol. 41. Linz: Trauner Verlag, 2013.

[5] M. Sonntag, Privacy and Security - Friends or Enemies?, vol. 46. Linz: Trauner Verlag, 2017.

[6] Z. Rahman, K. Suberamanian, H. Zanuddin, S. Moghavvemi, and M. H. N. M. Nasir, "Social Media Engagement Metric Analysis - 'Study on Fan Page Content,"” Journal of Telecommunication, Electronic and Computer Engineering (JTEC), vol. 8, no. 8, pp. 7176, Nov. 2016.

[7] Z. Vondra, Video Broadcast from Enterprise Social Network: Case Study, vol. 45. Linz: Trauner Verlag, 2016.

[8] A. Lisnik and A. Diacikova, Specifics of Using Social Networks in the Marketing in Slovakia, vol. 45. Linz: Trauner Verlag, 2016.

[9] K. Carnogursky, A. Diacikova, A. Chocholakova, and A. Lisnik, Sales Promotion and Using Social Media in the Slovak Internet Book Market, vol. 46. Linz: Trauner Verlag, 2017.

[10] W. Tafesse and A. Wien, "A framework for categorizing social media posts," Cogent Business \& Management, vol. 4, no. 1, p. 1284390, Jan. 2017.

[11] I. P. Cvijikj and F. Michahelles, "Online engagement factors on Facebook brand pages," Soc. Netw. Anal. Min., vol. 3, no. 4, pp. 843-861, Dec. 2013.

[12] L. de Vries, S. Gensler, and P. S. H. Leeflang, "Popularity of Brand Posts on Brand Fan Pages: An Investigation of the Effects of Social Media Marketing," Journal of Interactive Marketing, vol. 26, no. 2, pp. 83-91, May 2012.

[13] D.-H. Kim, L. Spiller, and M. Hettche, "Analyzing media types and content orientations in Facebook for global brands," Journal of Research in Interactive Marketing, vol. 9, pp. 4-30, Mar. 2015.

[14] K. Swani, B. P. Brown, and G. R. Milne, "Should tweets differ for B2B and B2C? An analysis of Fortune 500 companies' Twitter communications," Industrial Marketing Management, vol. 43, no. 5, pp. 873-881, Jul. 2014.

[15] R. Davis, I. Piven, and M. Breazeale, "Conceptualizing the brand in social media community: The five sources model," Journal of Retailing and Consumer Services, vol. 21, no. 4, pp. 468-481, Jul. 2014.

[16] J. Gummerus, V. Liljander, E. Weman, and M. Pihlström, "Customer engagement in a Facebook brand community,” Management Research Review, vol. 35, no. 9, pp. 857-877, Aug. 2012.

[17] B. Jahn and W. Kunz, "How to transform consumers into fans of your brand," Journal of Service Management, vol. 23, no. 3, pp. 344-361, Jun. 2012. 
[18] K. Antlova and P. Rydvalova, New Trends in E-Business Models, vol. 45. Linz: Trauner Verlag, 2016

[19] J. Čeněk, J. Smolík, and V. Svatošová, "Marketing on Social Networks: Content Analysis of Facebook Profiles of Selected Czech E-shops," Trends Economics and Management, vol. 10, no. 26, pp. 9-20, Sep. 2016.

[20] Alza.cz, "Historie a současnost," Alza, 2018. [Online]. Available: https://www.alza.cz/historie-a-soucasnost-art141.htm. [Accessed: 18-Apr-2018]. 